\title{
Teorías de la conspiración, fake news y COVID-19
}

\author{
Ricardo Mansilla Corona
}

If you are interested in paranoia and conspiracies, it is important to distinguish signals from noise.

Sean Carroll (físico, CalTech)

Las redes sociales le dan el derecho

de hablar a legiones de tontos que antes sólo hablaban en el bar después de un vaso de vino, sin dañar a la comunidad. Eran silenciados rápidamente y ahora tienen el mismo derecho a hablar que un Premio Nobel. Es la invasión de los necios.

Umberto Eco La Stampa (10 de junio de 2015)

a epidemia de COVID-19 ha perturbado de manera contundente y radical el desempeño de nuestras sociedades a nivel planetario. Su alto potencial de contagio ha conspirado junto a los patrones de movimiento propios de nuestras sociedades, cada vez más vigorosos, para expandir el virus hasta los rincones más alejados de nuestro mundo, sin respetar cla- 
ses sociales, estatus económicos y abolengos. La cantidad de casos activos creció de manera exponencial durante semanas en la mayoría de las naciones, saturando las capacidades de los sistemas de salud en casi todas las latitudes. Forzados por el incremento acelerado del número de casos, los gobiernos han debido tomar medidas extremas de distanciamiento social y de confinamiento con el objetivo de coartar la expansión del virus, lo cual ha perjudicado a las economías nacionales de forma muy significativa.

Estas medidas han tenido un impacto decisivo sobre el imaginario colectivo. En la era de internet, el ciudadano común se siente atrapado por la vorágine de cifras, datos y noticias, en ocasiones contradictorias, que encuentra en el mundo virtual. Muchas personas pueden pasar más tiempo en casa y lo ocupan buscando en línea respuestas a una situación incierta y que cambia rápidamente.

Por otra parte, en el ecosistema de la información del mundo virtual, las noticias tienen que competir por un recurso exiguo que le brindamos los seres humanos: nuestra atención. Una suerte de precepto de factura darwinista dicta que los mensajes más atractivos sobreviven, lo que convierte a la publicación de noticias en una alquimia donde se funden con frecuencia las verdades con las falsedades, la realidad envuelta en los claroscuros de la subjetividad. En este estado de cosas, es fácilmente asequible encontrar información que sea consistente con el sistema de creencias de cada cual, que reivindique nuestros sesgos de confirmación. Es un substrato muy adecuado para que florezcan las noticias falsas y las teorías de la conspiración.

\section{Algunas definiciones preliminares}

Es útil establecer con precisión los conceptos a los que se les dedican las páginas que siguen. En el Oxford English Dictionary hallamos la siguiente definición de teoría de conspiración:

Una teoría que afirma que un evento o fenómeno ocurre como resultado de una conspiración entre las partes interesadas. La creencia de que alguna agencia encubierta pero influyente (típicamente política en motivación y opresiva en intención) es responsable de un evento inexplicable. 
Llama la atención aquí el uso de la palabra "agencia”, asociada al calificativo "encubierta”. En ocasiones, las teorías de conspiración son echadas al vuelo por una sola persona con un carácter para nada encubierto. Bastaría recordar algunas teorías alrededor de la muerte del presidente John F. Kennedy ${ }^{1}$ (Goertzel, 1994; Olmsted, 2008), o sobre la caída de la Torres Gemelas de Nueva York (Dunbar y Reagan, 2006). En Wikipedia se puede leer:

Es una narración de un evento o situación que invoca una conspiración de grupos siniestros y poderosos, a menudo de motivación política, cuando otras explicaciones son más probables. El término tiene una connotación peyorativa, lo cual supone que la apelación a una conspiración se fundamenta en prejuicios o evidencia insuficiente. Las teorías de la conspiración se resisten a la verificación y se ven reforzadas por razonamientos circulares: tanto la evidencia contra la conspiración como la ausencia de evidencia para ella se reinterpretan como evidencia de su legitimidad, por lo que la conspiración se convierte en una cuestión de fe en lugar de algo que puede ser probado o refutado.

Se debe resaltar que, a pesar del carácter peyorativo adjudicado en esta definición a las teorías de conspiración, con frecuencia las mismas terminan convirtiéndose en la explicación más aceptada. ${ }^{2}$

Respecto al término fake news, ${ }^{3}$ en el Cambridge Dictionary encontramos: "Historias falsas que parecen ser noticias, difundidas en Internet o utilizando otros medios, generalmente creadas para influir en opiniones políticas o como una broma."

De nuevo Wikipedia es más explícita en su definición:

Son un tipo de bulo que consiste en un contenido pseudo periodístico difundido a través de portales de noticias, prensa, radio, televisión y redes sociales, cuyo objetivo es la desinformación. Se diseñan y emiten con la intención deliberada de engañar, inducir a error, manipular decisiones personales, desprestigiar o enaltecer a una institución, entidad o persona u obtener ganancias económicas o rédito político. Al presentar hechos falsos como si fueran reales, son consideradas una amenaza a la credibilidad de los medios serios y los periodistas profesionales, a la vez que un desafío para el público receptor. 
El primer uso de la frase conspiracy theory se remonta a 1871 y aparece en la página 141 del volumen 16 de The Journal of Mental Science para referirse a un pasaje de la novela Hard Cash; A Matter-of-Fact Romance, del escritor británico Charles Reade. La trama de esta novela se desarrolla en un sanatorio para enfermos mentales - que existía realmente- donde los pacientes eran maltratados por las autoridades de la institución. En el comentario que aparece en el número citado del Journal of Mental Science, su autor apela al término conspiracy theory para calificar la descripción hecha, al parecer con algún sustento, por el escritor Reade. Otra referencia muy lejana en el tiempo es un trabajo del 1909 sobre la derogación del compromiso de Missouri. ${ }^{4}$

A pesar de la supuesta modernidad del término fake news, de acuerdo con el Merriam-Webster Dictionary, su primer uso reconocido data de 1890 (Merriam-Webster, 2017). Dos notas periodísticas escritas los días 7 de junio y 7 de julio de 1890 en dos publicaciones de Estados Unidos son las primeras menciones reconocidas de este término.

Dado el carácter malintencionado de las fake news, es sustancial establecer aquí su diferencia con el simple concepto de "información errónea", que en lo referente al COVID-19 ha jugado un papel importante, toda vez que - como discutiremos al final - una parte considerable de las noticias transmitidas provienen de fuentes que no acreditaban los avales de erudición adecuados o simplemente no tenían un basamento científico claro. Un ejemplo paradigmático de esto es el periodo de contagio e incubación de la enfermedad, asunto sobre el cual se han elaborado un amplio conjunto de teorías, basadas en evidencia empírica insuficiente, en protocolos de investigación inadecuados o que sus autores no poseían la formación académica apropiada. La figura 1, construida a partir de dos fuentes autorizadas, muestra la duración del periodo de contagio para los diferentes tipos de enfermos.

En la actualidad, los conceptos de teoría de conspiración y fake news están indisolublemente unidos. A menudo, las teorías de la conspiración se establecen como la explicación sugerida para una fake news que alcanza mucha atención en el mundo virtual. Asimismo, una teoría de conspiración - basada originalmente en un hecho real, incontrovertible, pero que 
reclama una explicación- puede generar fake news que, como vástagos, se apoyan en su trama.

Figura 1. Duración de las etapas de contagio para los cuatro diferentes tipos: asintomáticos, moderados, severos y críticos

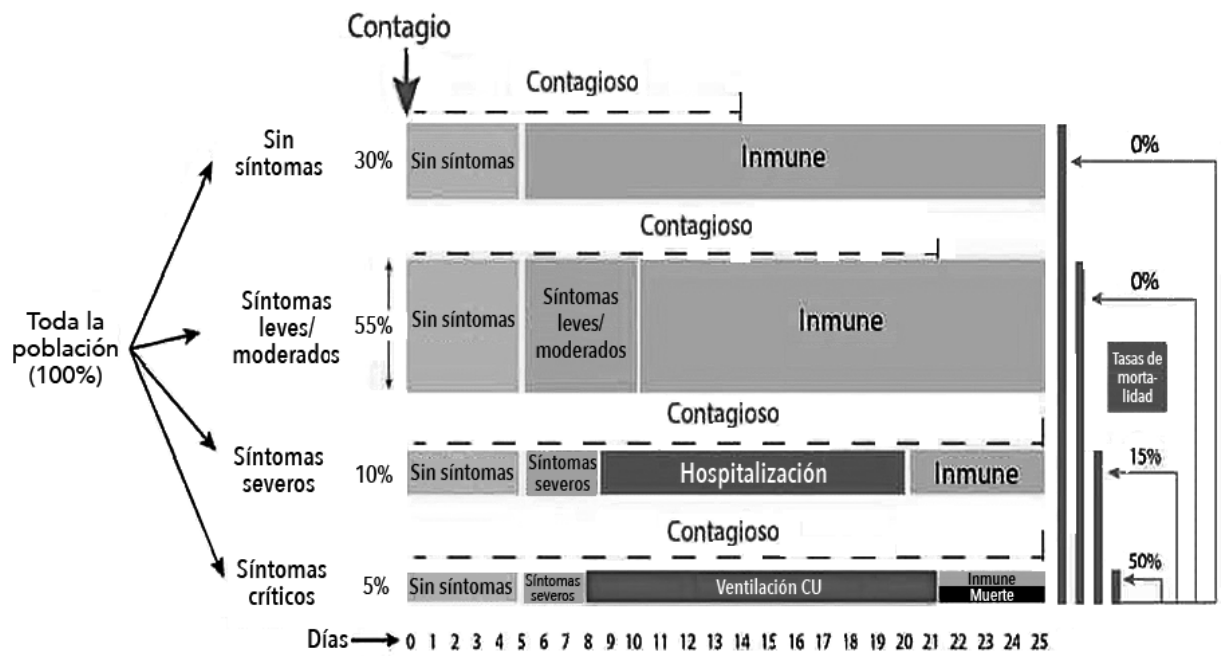

Fuentes: S.A. Lauer et al. 2020. "The Incubation Period of Coronavirus Disease (covID-19) From Publicity Reported Confirmed Cases: Estimation and Application", Ann. Inter. Med., 10 de marzo; Neil M. Ferguson et al. 2020. Impact of Non-Pharmaceutical Intervitions (NPIS) to Reduce CovID-19 Mortality and Healthcare Demand, Imperial College Covid-19 Team, 16 de marzo; Yang Liu et al. 2020. "Viral Dynamics in Mild and Severe Cases of Covid-19", The Lancer, 19 de marzo.

\section{El sesgo a favor de las noticias falsas en las redes sociales}

Vosoughi et al. (2018) mostraron, más allá de cualquier duda razonable, que las noticias falsas se difundían más rápida y profundamente que las noticias verdaderas en las redes sociales. El trabajo se basaba en 126000 historias publicadas en Twitter cada una de las cuales fue cotejada en su validez o falsedad por seis organizaciones independientes de verificación de hechos. La concordancia en el veredicto de las diferentes clasificaciones sobrepasaba 95\%. Se mostró que las noticias falsas eran más atractivas que las verdaderas, lo que sugería que las personas tenían una mayor proclividad a compartir las 
primeras. Como es conocido, los bots digitales — no humanos- de internet transmiten por igual tanto noticias verdaderas como falsas, ${ }^{5}$ por tanto, tal sesgo hacia las noticias falsas era sostenido por humanos.

Este hecho está relacionado con una afirmación hecha al principio de estas páginas. Los generadores de noticias saben que tienen que competir por la atención de las personas y este es un recurso escaso en el mundo virtual, toda vez que la cantidad de información emitida sobrepasa por muchos ordenes de magnitud la posibilidad humana de atenderla. Por tanto, hacer llamativas las entregas es un asunto de simple sobrevivencia. ${ }^{6}$ Sin embargo, en lo que respecta al COVID-19, esta situación general presentada en el trabajo antes mencionado no era tan clara. En marzo de este año se publicó un trabajo cuyo resultado esencial era un análisis comparativo de los contenidos publicados en cuatro plataformas de redes sociales diferentes - Twitter, Youtube, Reddit y Gab- durante la emergencia de salud COVID-19 (Cinelli, et al., 2020). En el análisis de la información cuestionable quedó claro que $\mathrm{Gab}^{7}$ es el entorno más susceptible a la difusión de información errónea, muy a tono con las políticas permisivas y de no supervisión de esta red. Sin embargo, los patrones de difusión de la información confiable y dudosa no presentaban diferencias significativas. La conclusión más transcendental de este trabajo es que, en lo que se refiere al covid-19, la difusión de información está impulsada por el paradigma de interacción impuesto por las redes sociales específicas, esto es, por las reglas de limitaciones de mensajes de odio, raciales, misóginos y semejantes y por los patrones de interacción específicos de grupos de usuarios comprometidos con el tema.

Este tipo de sesgo, en lo que se refiere a noticias falsas o verdaderas y teorías de la conspiración relacionadas con el COVID-19 en las redes sociales, se replica de forma similar en otros medios de comunicación masiva. La Harvard Kennedy School publicó en abril de este año un trabajo donde se mostraba, con los resultados de una amplia encuesta realizada en la población general, que el uso de las grandes cadenas televisivas de Estados Unidos - NBC News, por ejemplo- para la búsqueda de información tenía una fuerte correlación dentro de la muestra de encuestados con el interés de estos por obtener testimonios fidedignos sobre la mortalidad del COVID- 
19 (Albarracín y Jamieson, 2020). Por otra parte, los participantes del estudio que afirmaban hacer uso de los grandes medios impresos - New York Times, por ejemplo- tenían como interés básico la búsqueda de información sobre protección contra la infección. Aquellos que manifestaban su proclividad por medios de difusión conservadores -Fox News, por ejemplo- eran fuertemente proclives a las teorías de la conspiración, en particular aquella que sostenía que el Centro de Control de Enfermedades de Atlanta, Georgia (CDC, por sus siglas en inglés) exageraba la gravedad del COVID-19 para dañar la presidencia de D. Trump.

Sin ánimo de establecer una clasificación exhaustiva de los diferentes tipos de fake news y teorías de la conspiración relacionadas con el COVID-19, se puede establecer la siguiente agrupación en términos del sujeto de las teorías generadas: 1) en contra de personalidades públicas; 2) en contra de gobiernos; 3) en contra de grupos étnicos; 4) en contra de toda la humanidad; y 5) acerca de curas, medicamentos y procedimientos profilácticos.

En lo que se refiere a teorías de conspiración cuyos protagonistas son figuras públicas, las más difundidas son las relacionadas con Bill Gates, el fundador de Microsoft, quien ha financiado esfuerzos para controlar el virus con tratamientos, vacunas y tecnología. De acuerdo con algunas teorías, el creó el virus con la intención de controlar a la humanidad por medio de la vacuna que su propia fundación - la Fundación Bill y Melinda Gatesfinanciaría. Más aún, patentó la molécula del virus. Roger Stones, asesor por algún tiempo del presidente D. Trump — que recibió un indulto presidencial recientemente por hacer declaraciones falsas, manipular a un testigo y obstruir la investigación de la interferencia de Rusia en las elecciones de 2016-, declaró en su momento que él "nunca confiaría en una vacuna para el COvid-19 que Bill Gates hubiera financiado” (Philip Ball y Amy Maxmen, 2020: 371). El conocido cantante español M. Bosé se sumó a este esfuerzo conspirativo con las declaraciones publicadas en su cuenta de Twitter. ${ }^{8}$ De hecho, se ha llegado a afirmar que en la fundación de Gates hay una puerta encima de la cual se observa la inscripción: "Centro para la Reducción Global de la Población Humana” (Maldita.es, 2020a). 
En lo que respecta a teorías de conspiración contra gobiernos, el intercambio de acusaciones entre las administraciones de China y Estados Unidos ha alcanzado las primeras planas de la mayoría de los medios de información globales. De una parte, el secretario de Estado M. Pompeo ha afirmado reiteradamente, sin mostrar evidencia, que la pandemia de COVID19 está vinculada a un laboratorio en Wuhan que investiga coronavirus de murciélago. Muchos científicos estiman que es poco probable que el SARsCOV-2 tenga su origen en un laboratorio. Aun así, algunos expertos en bioseguridad lo ven como una posibilidad ${ }^{9}$ (Mansilla, 2020). En particular, R. Ebright, profesor de la Universidad Rutgers y experto en bioseguridad piensa que una investigación a fondo sobre este asunto está completamente justificada. Los gobiernos de Canadá, Alemania, Suecia y Australia han apoyado la investigación (Hvistendahl, 2020). A todo esto, debe agregarse el arresto, el 28 de enero, del profesor Charles Lieber, jefe del Departamento de Bioquímica de la Universidad de Harvard, y una referencia mundial en el campo de las nanotecnologías. Según el New York Times (The Obsevateurs, 2020), Lieber firmó un acuerdo en 2011 para actuar como científico de alto rango en la Universidad Tecnológica de Wuhan que, como es conocido, fue el epicentro inicial del coronavirus.

En la dirección contraria, el gobierno de Pekín afirma que el SARS-Cov-2 fue introducido en China por soldados estadounidenses durante unas maniobras militares conjuntas. El vocero del Ministerio de Relaciones Exteriores chino, Zhao Lijian, sugirió recientemente en un tuit, publicado en mandarín e inglés, que el "paciente cero" en la pandemia global podría haber venido de Estados Unidos (Milenio, 2020a).

La producción de fake news y teorías de conspiración dirigidas a grupos étnicos ha tenido un amplio espectro de manifestaciones que incluyen el discurso de odio, la discriminación racial y la misoginia. Por solo citar un ejemplo muy demostrativo, el periodista T. Méndez, en su programa ADN, del canal de noticias C5N de la TV argentina, se fundamentó en teorías conspirativas antiquísimas sobre la culpabilidad de los judíos en los males del mundo para afirmar que eran los ejecutores de la propagación del COVID-19 (Lubochiner, 2020). 
Investigadores de la Universidad George Washington de Estados Unidos, dirigidos por N. Johnson, publicaron recientemente un trabajo donde muestran que contenido malicioso relacionado con el covid-19, que incluye discursos de odio, desinformación e información errónea, se ha difundido dentro del mundo virtual extendiéndose rápidamente más allá del control de cualquier plataforma de redes sociales (Velásquez et al., 2020). Johnson y su equipo toman prestado de ciertas teorías físicas los conceptos de "multiverso" y "agujero de gusano" para caracterizar las áreas de las redes sociales donde, con personalidad propia, se cultivan mensajes de odio y de desinformación deliberada. La figura 2, tomada del trabajo de Johnson y sus colaboradores, muestra una representación de estos multiversos y de los huecos de gusano que los unen. La razón que tienen los generadores de mensajes de odio para la creación de estos últimos es evitar la vigilancia que se ejerce en muchas plataformas digitales en contra de este tipo de mensaje. Los huecos de gusanos son vínculos entre plataformas bien establecidas (Facebook, Gab, Telegram) donde se engendran estas noticias que después son conectadas con estas plataformas a partir de vínculos que no pueden ser supervisados por los administradores de las grandes redes sociales. De esta manera, los mensajes de odio circulan y se difunden en las redes sin la posible invalidación de estos por parte de los algoritmos supervisores de las redes sociales.

También se han desarrollado teorías conspirativas que involucran a toda la sociedad. Al inicio de la pandemia se propagó en las redes sociales la teoría de que el virus SARS-COV-2 había sido diseñado para matar a los ancianos y de esta manera ahorrar en pago de pensiones y costos de tratamientos médicos prestados por los servicios de seguridad social de los gobiernos. El sustento de esta idea era básicamente la conocida característica de este virus de atacar con mayor intensidad a este grupo de edad. Esta teoría de conspiración no daba ninguna indicación acerca de quiénes estaban detrás de este exterminio - una suerte de grupo Iluminatti con capacidad para dominar al mundo. 
Figura 2. Una representación de estos multiversos y de los huecos de gusano que los unen

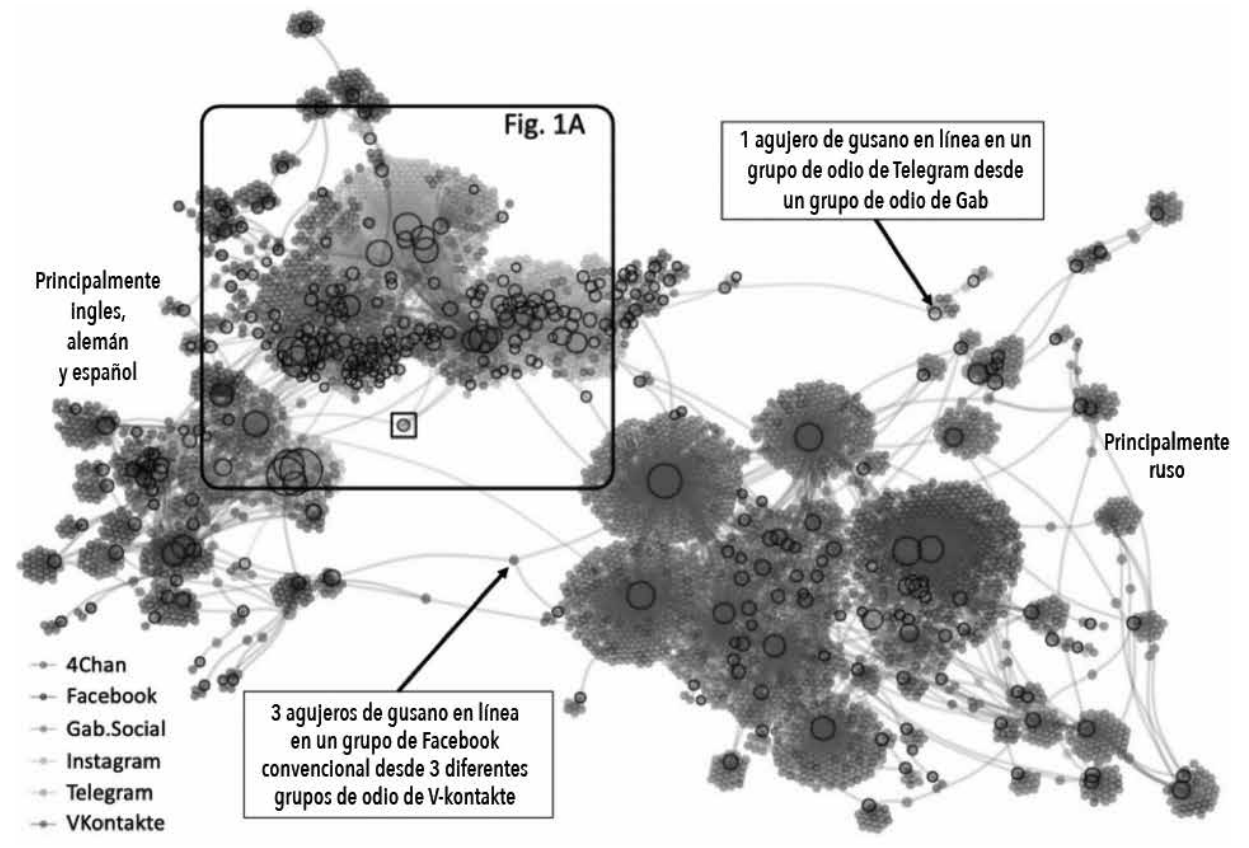

Fuente: tomada del trabajo de N. Velásquez et al. (2020). Los multiversos son grandes conglomerados de usuarios unidos entre sí por aficiones, intereses mutuos y sesgos acerca de ciertos temas. Los huecos de gusano son la estrategia usada por los generadores de los mensajes de odio para evitar el control que se ejerce en muchas plataformas digitales en contra de mensajes de contenido inapropiado.

Más adelante, cuando la pandemia mostró que era muy letal en personas con ciertas condiciones médicas previas —obesidad e hipertensión- la teoría evolucionó al siguiente planteamiento: el virus SARS-COV-2 fue diseñado para matar a personas con problemas de salud y de esta manera ahorrar en pago de pensiones y costos de tratamientos médicos prestados por los servicios de seguridad social de los gobiernos.

En lo referente a fake news y teorías de conspiración concernientes a medicamentos, curas y procedimientos profilácticos es donde se observa la más amplia diversidad y abundancia de crónicas. Han acaparado mucha atención, por ejemplo, las afirmaciones de que la vacuna contra el coronavirus 
se fabrica con base en células de fetos abortados (Maldita.es, 2020b), o bien que el IMSS está matando a los pacientes en sus clínicas para robarles el líquido de las rodillas y venderlo internacionalmente a mafias por 10000 dólares. Los médicos complotados reciben 100 dólares por pieza (Niusgeek, 2020).

Mención aparte en esta categoría merecen los desatinos de funcionarios públicos que, en el ejercicio de sus cargos, hacen afirmaciones imprudentes que sin duda pueden conspirar contra la salud de la ciudadanía. Un ejemplo paradigmático de esto es la sugerencia del presidente de Estados Unidos D. Trump de ingerir Lysol (Milenio, 2020b), o los llamativos comentarios del presidente de México, A. M. López Obrador, quien el 28 de febrero afirmó que la pandemia de COVID-19: "No es, según la información que se tiene, algo terrible, fatal. Ni siquiera es equivalente a la influenza". Más adelante, el 4 de marzo comentaba: "Miren, lo del coronavirus, eso de que no se puede uno abrazar; hay que abrazarse, no pasa nada". Por último, el 18 de marzo afirmaba: "El escudo protector es como el detente (...) El escudo protector es la honestidad, eso es lo que protege, el no permitir la corrupción (...) detente, enemigo, que el corazón de Jesús está conmigo", en referencia a su protección en contra de la enfermedad. Conviene aquí señalar también el pésimo desempeño del subsecretario de Prevención y Promoción de la Salud de México, el doctor Hugo López Gatell que ha mantenido una errática actuación en el desempeño de su cargo, ofreciendo información a la ciudadanía sin el adecuado sustento científico. El 11 de febrero declaró: "No se necesitan hospitales exclusivos para la atención de coronavirus", afirmación que sostuvo aún el 6 de marzo, en contra de toda la evidencia internacional sobre el tema. Como es conocido, finalmente se establecieron hospitales completamente dedicados a la atención de la pandemia. El 12 de marzo expresó: "No hay demostración de que estas medidas extremas (cierre de fronteras) puedan ayudar a disminuir el riesgo de transmisión". No obstante, 9 días después México y Estados Unidos acordaron el cierre de las fronteras para mitigar el contagio. El 13 de marzo, a pesar de la evidencia observada en otros países, se expresó en contra del cierre de escuelas al considerarlo "no indispensable". Afortunadamente, al día siguiente, la SEP decidió —al igual 
que muchas otras autoridades educativas en el mundo- la suspensión de clases como medida para prevenir contagios. Después de afirmar en varias ocasiones que el cubrebocas no era necesario, más aún que era contraproducente —en contra de toda la evidencia a nivel internacional—, el 25 de mayo afirmó: "El cubrebocas será una medida auxiliar para evitar la propagación del COVID-19”. El 27 de mayo afirmó que las pruebas rápidas eran un "desperdicio de tiempo, de esfuerzo, de recursos". No obstante, respetados especialistas de todas partes del mundo han certificado la pertinencia de hacer pruebas masivas. Para no hacer esta lista de torpezas innecesariamente larga baste agregar que el 17 de mayo propuso la idea - que califica legítimamente como una teoría de conspiración- de que el SARS-COV-2 habría entrado a México por medio de turistas mexicanos de altísimos ingresos que viajaban en un jet privado.

Estos desatinos tienen sin duda consecuencias sobre la ciudadanía, en particular sobre las capas menos educadas de la población. Un estudio reciente, elaborado por investigadores del CRIM de la UNAM (Hernández, 2020), muestra que $71.2 \%$ de las defunciones son de personas con escolaridad menor o igual al sexto grado de primaria. Como era de esperarse, aquellos ciudadanos para los que el sustento de sus familias depende de salir diariamente a la calle - iy que debían usar cubrebocas! - desafiando las medidas de confinamiento y de sana distancia, son también el sector más castigado de las defunciones, acumulando $68 \%$ de las mismas. ${ }^{10}$

En el editorial del 4 de junio de 2020 de Nature Medicine se puede leer: "Los funcionarios de gobierno que difunden afirmaciones no respaldadas sobre el nuevo coronavirus socavan la confianza pública en la ciencia y en los esfuerzos de salud pública que son esenciales para controlar la pandemia de COVID-19" (2020: 805). Obviamente el editorial de la revista no se refería únicamente a México.

El sector académico tampoco ha permanecido inmune a estos problemas. El conocido mantra de "publica o perece", que se cierne como espada de Damocles sobre la comunidad científica, ha ocasionado algunos perjuicios en la calidad de la copiosa literatura publicada en torno al COVID-19. Recientemente, Nature publicó un trabajo sobre la alarmante cantidad de artículos que después de haber sido publicados han debido corregirse. Lla- 
ma la atención que esta plaga ha afectado a las más prestigiosas revistas a nivel internacional como Lancet o el New England Journal of Medicine (Vuong, 2020). Los espacios de difusión de noticias son con frecuencia ocupados por charlatanes que, sin la preparación académica adecuada, se deciden a pontificar sobre algún aspecto de la pandemia. Una buena valoración sobre este tema la ha hecho C. Bergstrom, biólogo de la Universidad de Washington en Seattle:

Donde los científicos expertos fueron honestos sobre su ignorancia acerca del COVID-19 se generó un vacío de incertidumbre que permitió que fuentes de reputación superficial saltaran al público sin verdadera experiencia. Aquí se incluyen a académicos con escasas credenciales para pronunciarse sobre epidemiología, o analistas de datos que eran buenos para trabajar con números, pero carecían de una comprensión profunda de la ciencia subyacente (Ball y Maxmen, 2020: 372).

Todos debemos actuar con responsabilidad, sobre todo aquellos cuyas acciones son proclives a provocar daños a otros seres humanos. Esto incluye obviamente a científicos y figuras públicas. Recientemente el escritor español y académico de número de la Real Academia Española, A. Muñoz Molina decía que la calamidad que estamos viviendo nos había servido al menos para reconocer la autoridad de las personas que saben. La ciudadanía precisa recibir la información más clara y necesaria posible. No traicionemos ese compromiso.

\section{Referencias}

Albarracín, D. y K.H. Jamieson. 2020. "The Relation between Media Consumption and Misinformation at the Outset of the SARS-COV-2 Pandemic in the US", The Harvard Kennedy School Misinformation Review. Special Issue on COVID-19 and Misinformation, abril, en <https://doi.org/10.37016/mr-2020-012>.

Cinelli, M. et al. 2020. “The Covid-19 Social Media Infodemic”, en <https://arxiv.org/ pdf/2003.05004.pdf>.

Dunbar, D. y B. Reagan (eds.). 2006. Debunking 9/11 Myths: Why Conspiracy Theories Can't Stand Up to the Facts, Nueva York, Hearts Books.

Goertzel, T. 1994. "Belief in Conspiracy Theories", Political Psychology, vol. 15, núm. 4, pp. 731-742. 
Hernández Bringas, H. 2020. "Mortalidad por Covid-19 en México. Notas preliminares para un perfil sociodemográfico", Notas de coyuntura del CRIM, núm. 36, junio, pp. 1-7, en <https://web.crim.unam.mx/sites/default/files/2020-06/crim_036_he ctor-hernandez_mortalidad-por-covid-19_0.pdf>.

Hvistendahl, M. 2020. "In Its Zeal to Blame China for Coronavirus, the Trump Administration is Thwarting Investigations into the Pandemic's Origins", en The Intercept, 19 de mayo, en <https://theintercept.com/2020/05/19/coronavirus-pandemicorigin-trump-china/>.

Lubochiner, E. 2020. "Un periodista de la TV argentina acusa a los judíos de crear el Coronavirus", en Aurora-Israel, 5 de abril, en <https://www.aurora-israel.co.il/unperiodista-de-la-tv-argentina-acusa-a-los-judios-de-crear-el-coronavirus $>$.

Maldita.es. 2020a. "El coronavirus y sus bulos: 680 mentiras, alertas falsas y desinformaciones sobre Covid-19", 4 de julio, en <https://maldita.es/malditobulo/ 2020/07/17/coronavirus-bulos-pandemia-prevenir-virus-covid-19/>.

. 2020b. "El movimiento antivacunas y la COVID-19: no, la vacuna del coronavirus no 'se fabrica a base de células de fetos abortados"', en Maldita.es, 17 de junio, en <https://maldita.es/malditaciencia/2020/06/17/el-movimiento-antivacunasy-la-covid-19-no-la-vacuna-del-coronavirus-no-se-fabrica-a-base-de-celulas-defetos-abortados>.

Mansilla, R. 2020. "Las doce letras de la pospandemia", Observatorio de las Ciencias Sociales del Consejo Mexicano de Ciencias Sociales, en <https://www.comecso. $\mathrm{com} /$ blog-ciencias-sociales-digitales/doce-letras-de-la-pospandemia $>$.

Merriam-Webster. 2017. “The Real Story of 'Fake News'. The Term Seems to Have Emerged Around the End of the 19th Century", en <https://www.merriam-webster. com/words-at-play/the-real-story-of-fake-news $>$.

Milenio. 2020a. "EU y China se acusan de haber iniciado pandemia de coronavirus". en Milenio, 16 de marzo, en <https:/www.milenio.com/internacional/mas-interna cional/covid-19-eu-china-culpan-mutuamente-iniciar-pandemia $>$.

Milenio. 2020b. 'Lysol' pide no ingerir sus productos para 'noquear' el covid-19", en Milenio, 24 de abril, en <https://www.milenio.com/internacional/donald-trumpsugiere-lysol-cura-covid-19-fabricante-niega $>$.

Nature Medicine. 2020. "It is not the Time for Science Fiction", en Nature Medicine, 26 de junio, p. 805, en <https://www.nature.com/articles/s41591-020-0955-8.pdf>.

Niusgeek. 2020. "La verdad detrás del meme: ¿Te roban el líquido de las rodillas para venderlo a la mafia?", en Niusgeek, 7 de mayo, en <https://rpp.pe/tecnologia/redessociales/virales-la-verdad-detras-del-meme-te-roban-el-liquido-de-las-rodillaspara-venderlo-a-la-mafia-noticia-1263842>.

Olmsted, K. 2008. Real Enemies: Conspiracy Theories and American Democracy, World War I to 9/11, Nueva York, Oxford University Press. 
Philip Ball, Amy Maxmen. 2020. “The Epic Battle Against Coronavirus Misinformation and Conspiracy Theories", Nature, núm. 581, 28 de mayo, pp. 371-374, en <https:// www.nature.com/articles/d41586-020-01452-zNature>.

Velásquez, N., R. Leahy, N.J. Restrepo, Y. Lupu, R. Sear, N. Gabriel y N.F. Johnson. 2020. "Hate Multiverse Spreads Malicious Covid-19 Content Online beyond Individual Platform Control", en <arXiv preprint arXiv:2004.00673>.

Vosoughi, et al. 2018. "The Spread of True and False News Online", Science, núm. 359, pp. 1146-1151.

Vuong, Q. H. 2020. "Reform Retractions to Make them More Transparent", en Nature, 8 de junio, en $<$ https://www.nature.com/articles/d41586-020-01694-x>.

\section{Notas}

${ }^{1}$ A estas alturas la cantidad de páginas dedicadas al asunto es enorme.

${ }^{2}$ Durante mucho tiempo se especuló que John Lennon estaba bajo la vigilancia del gobierno de Estados Unidos, debido a su canción "Give Peace a Chance". El historiador Jon Wiener, de la Universidad de California en Irvine, estuvo 14 años luchando para obtener acceso a los archivos secretos del FBI sobre John Lennon. El FBI se negó a liberar muchos de los documentos, aduciendo que su liberación pondría en peligro la seguridad nacional. El caso de Wiener llegó hasta la Corte Suprema antes de que el FBI aceptara llegar a un acuerdo. El resultado de su trabajo puede encontrarse en el libro Gimme Some Truth: The John Lennon FBI Files, University of California Press, 1999.

${ }^{3}$ En lo que sigue utilizaremos este anglicismo, toda vez que su uso se ha vuelto universal.

${ }^{4}$ El Compromiso de Missouri fue un acuerdo aprobado en 1820 entre los grupos a favor y en contra de la esclavitud dentro del Congreso de Estados Unidos. Consistía básicamente en la regulación de la esclavitud en los territorios occidentales. Prohibía la esclavitud en el antiguo territorio de Louisiana al norte del paralelo $36^{\circ}$, excepto dentro de los límites del estado propuesto de Missouri. En el American Historical Review - vol. 14, núm. 4, 1909-, aparece una reseña del libro The Repeal of the Missouri Compromise: Its Origin and Authorship, de P. Ray. El autor de la reseña era A. Johnson. En el libro se desarrollaba la teoría de conspiración que ponía al senador de Estados Unidos y presidente protempore de la Unión Americana D. Atchinson como el cerebro detrás de la derogación del compromiso de Misouri. Según P. Ray, esta teoría habría sido elaborada por el coronel del ejército J. A. Parker.

${ }^{5}$ Por el momento. En esto jugará un papel importante el análisis semántico de los lenguajes naturales por medio de la Inteligencia Artificial. 
${ }^{6}$ El sistema de financiamiento universal de las plataformas en internet es a través del cobro por el uso de los espacios dentro de las mismas dedicados a la promoción de productos - las llamadas "adds". El número de visitas aumenta los ingresos de los propietarios de las plataformas. Por lo tanto, la cantidad de referencias hechas a informaciones publicadas en las plataformas aumenta el número de visitas y en consecuencias los ingresos.

${ }^{7}$ Gab es una red social cuyo modelo de negocio esta basado en permitir la libre expresión de sus usuarios a partir principalmente de sus políticas permisivas. El sitio reivindica la absoluta libre expresión de sus miembros.

${ }^{8}$ En $<$ https://twitter.com/BoseOfficial/status/1270382117545893888>.

${ }^{9}$ El SARS-Co-2 se diferencia de otros coronavirus por 12 nucleótidos que son los causantes, según algunos especialistas, de su alta capacidad de contagio. Dados los recientes avances en la tecnología CRISPR es muy difícil sustraerse a la tentación de especular acerca de la eventualidad de que el SARS-COV-2 haya sido construido en algún laboratorio, en <https://www.comecso.com/blog-ciencias-sociales-digitales/doceletras-de-la-pospandemia $>$.

${ }^{10} \mathrm{El}$ trabajo del CRIM-UNAM mencionado dice que ese $68 \%$ lo componen amas de casa, operarios de maquinaria, vendedores ambulantes, conductores, trabajadores domésticos artesanos y obreros. 